\title{
Oral and Perioral Piercing Complications
}

\author{
N. Escudero-Castaño, M.A. Perea-García, J. Campo-Trapero, Cano-Sánchez and \\ A. Bascones-Martínez*
}

\author{
School of Dentistry, Complutense University of Madrid. 28040 madrid-Spain
}

\begin{abstract}
Background. The oral an perioral piercing has a long history as part of religious, tribal,cultural or sexual symbolism and nowdays there is a high incidence of oral and perioral piercing in the adolescent population. This practice has a long history as part of religious, tribal, cultural or sexual symbolism. This article reviews current knowledge on injuries or diseases that might be produced by piercing in the oral cavity. We propose a classification to diagnosed the pathologies related to oral an perioral piercing

Methods. A search was conducted of articles in PubMed, Scielo published between 1997 and 2007, using the key words "oral and perioral, piercing ", " "oral, piercing and disease", “recessions and oral piercing". It has reviewed about twentythree articles 17 were narrative reviews and 6 case series

Results. A review was carried out on the origins of oral and perioral body piercing and its local implications, classifying the different alterations like recessions, systemic implications that it can produce in the oral and perioral cavity.

Conclusion. Patients with oral and perioral piercing should be regularly followed up because of the possible development of different types of adverse effects.

Clinical implications. Adverse effects of oral and perioral piercing can be systemic, with transmission of infectious diseases such as hepatitis B or C, or can be local, with alteration of oral mucosae or even of dental structures.
\end{abstract}

Key Words: Oral ,perioral piercing and perioral diseases.

\section{INTRODUCTION}

Oral and perioral piercing involve the insertion of jewellery into the tongue, lip, cheek, frenum, uvula or other part of the mouth, has long been practiced for religious, tribal, cultural, sexual or identity reasons [1]. The earliest known representation of this piercing was in the figure of a dog created in Egypt in around 1500 BC, when it was considered a symbol of royalty. For ancient Mayans, piercing was a symbol of spirituality, virility and courage. Eskimos inserted a "labret" into the lower lip as a symbol of passage to adulthood in boys and as an act of purification in girls. The piercing of lips, cheek or tongue was also a traditional practice in Hindu, Chinese and American Indian cultures [2]. In Southern India, a vow of silence was accompanied by tongue piercing [3].

In developed countries, piercing became fashionable with the punk movement and then as part of a wider "body art", i.e., the voluntary modification of physical appearance by tattoos, branding, scars or piercing $[4,5]$. Hypoallergenic and non-toxic materials are used for piercing jewellery, e.g., 14 or $18 \mathrm{~K}$ gold, titanium, stainless steel, niobium, tygon, acrylic, stone, wood, bone, or ivory $[2,3,5,6]$.

Four types of piercing jewellery are applied in the oral/perioral area. One type is the labret, a bar with ball, disc

*Address correspondence to this author at the Department of Oral Medicine and Periodontology, School of Dentistry, Complutense University of Madrid , 28040 madrid-Spain; E-mail: antbasco@odon.ucm.es or point at one end and flat closing disc at the other (Fig. 1). Another type is the barbell, a straight or curved bar with balls at each end (Fig. 1). A third type is an unclosed ring with a ball at one or both ends $[4,6]$. In a fourth type, two components of the stud are held together by a magnetic force 10 -fold greater than that of a conventional magnet [5]. Various authors have reported the adverse effects that can be produced during the act of piercing and as a result of the constant presence of this jewellery [6].

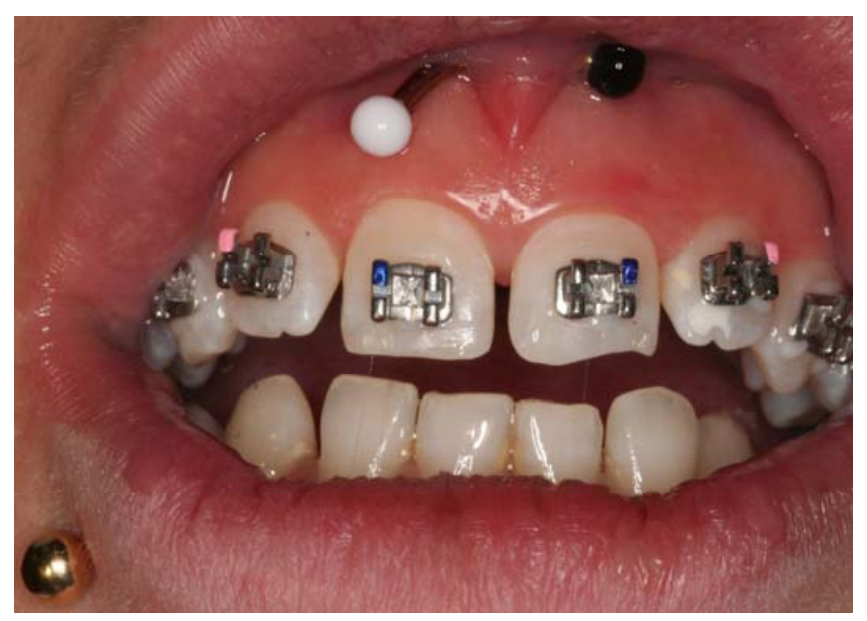

Fig. (1). Patient with 2 types of piercing, labret and barbell. 


\section{MATERIAL AND METHODS}

We made a review of the papers 17 were narrative reviews and 6 case series which explain the pathologies related to oral and perioral piercing and we structure the article in a classification which explain the involment of oral and perioral piercing in the organism.

\section{COULD ANY DISEASE BE CAUSED DURING THE INSERTION OF PERIORAL OR ORAL PIERCINGS?}

The tongue is highly vascularised and innervated, and controlled bleeding can be expected during the piercing of this organ. In fact, there is evidence that a major haemorrhage can be produced $[5,7]$. Piercing sites are innervated with sensory or motor fibres, and special care must be taken to avoid cutting any nerves and causing damage or paresthesias $[4,5]$. All material used for the piercing must be sterile to avoid transmission of disease, e.g., hepatitis B and C, HIV, herpes simplex virus, Epstein-Barr virus, Candida albicans, tetanus, syphilis or tuberculosis.

\section{COULD PIERCINGS AFFECT X-RAYS?}

Oral and perioral piercings produce radiopaque areas and must be not be worn during X-ray examinations. Thus, for panoramic X-.rays, any metal object above the neck must be removed [4-6].

\section{ARE PIERCINGS RELATED TO PAIN, INFLAMMA- TION, INFECTION OR ANAPHYLACTIC REAC- TIONS?}

Besides bleeding, the most frequent complication of piercing is painful ulceration, reported in almost half of recipients, followed by inflammation, described in around $9 \%$ of cases $[3,4,8]$. In the tongue, these primary lesions disappear after 3-5 weeks [9]. The onset of local inflammation is at 6-8 $\mathrm{h}$ after the piercing, reaching a peak on day 3 or 4 . Inflammation can persist for weeks and, although usually temporary, may produce a granulomatous inflammation in response to the foreign body, interfering with mastication and swallowing and sometimes even responsible for asphyxia or respiratory difficulties [5].

Many authors have described infections as a common complication of oral/perioral piercing, observed in $10-20 \%$ of cases. Tongue piercings appear especially prone to infection, by Staphylococcus aureus, A group Streptococcus, Pseudomonas aeruginosa, Erysipelas and $\beta$-haemolytic Streptococcus, among other microorganisms. The proximity of lymph-node chains to this initially local focus of infection may favour its spread, leading to speech impairment, airway obstruction or even damage to vital organs, e.g., endocarditis $[5,7,10-12]$. The spread of these microorganisms to the bloodstream can cause bacteraemia $[2,4,6]$, which is normally asymptomatic but can produce fever, shivers, tremors and a reddening around the jewellery. In isolated cases, sepsis can lead to septic shock, a life-threatening disease. Ludwig's angina can also be induced by the presence of anaerobic microorganisms related to an oral piercing $[5,6,8$, 13].

Anaphylactic reactions can be produced by some of the materials inserted [5], e.g., nickel, the metal that causes most contact allergies. The most widely reported allergic reaction in piercing is contact dermatitis produced by nickel, chromium or nickel-cobalt $[4,5,7,14]$. In the mid-1990s, the European Union issued a directive to limit the amount of nickel in all products in direct contact with human tissue, with a limit of $0.05 \mathrm{~g}$ for the nickel used in oral/perioral piercing jewellery. It also recommended that gold used for this purpose should be at least $14-18 \mathrm{~K}[4,5]$.

\section{IS THERE A RELATIONSHIP BETWEEN PIERCING AND BACTERIAL PLAQUE?}

A greater presence of plaque can be produced at the site of oral/perioral piercings due to the difficulty of maintaining hygiene and the retention of food remains, creating an ideal environment for a large accumulation of plaque and calculus [3]. Moreover, constant contact with a barbell in the tongue, for example, increases the probability of supra- and subgingival plaque accumulation at the lower front teeth [10]. These accumulations can produce halitosis and possible infection [8]. Thus, oral piercings have been associated with gingivitis [8], which requires the presence of bacteria in plaque for its onset, although factors related to microorganisms and host predisposition also affect this pathogenesis [15].

\section{DO ORAL AND PERIORAL PIERCINGS CAUSE TIS- SUE ALTERATIONS?}

Mucosal trauma produced by oral/perioral piercings (Figs. 2 and 3) can cause localized erythema, the most frequent piercing-related alteration alongside oedema. Piercing can be followed by hyperplastic scarring [4], which may be accompanied by pain and oedema [5,6]. Hypertrophic or cheloid scarring can also occur, possibly influenced by the presence of systematic disease, medication or the smoking habit, although tobacco was reported not to be a statistically significant factor [16]. Tissue overgrowth can be caused by continuous movement of the jewellery in the inserted tissue [9] and surgery may even be required, with a high risk of recurrence if the piercing is repeated [5]. In some cases, the insertion wound can become covered with epithelium, complicating removal of the jewellery [4]. Continuous contact with the jewellery can also cause alterations to the lingual papillae, which can produce a reduced ability to taste things (to taste sweet, sour, bitter, or salty substances) [5].

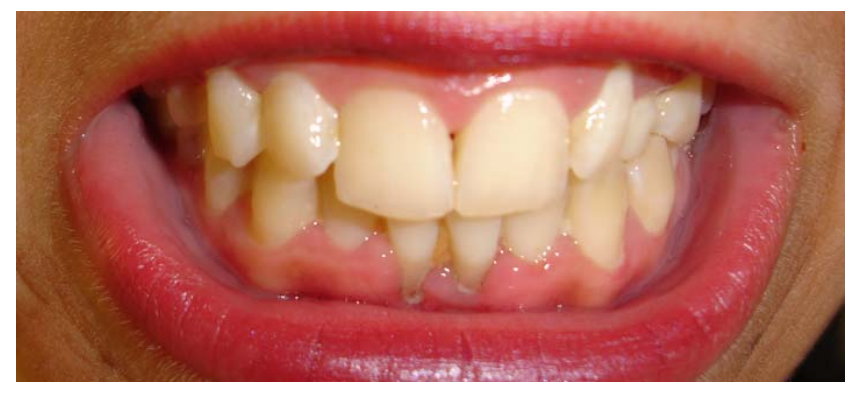

Fig. (2). Local recessions in the lower jaw produced by oral piercing.

The presence of piercings in the oral/perioral cavity can cause various lesions, including oedema and reactive lesions, e.g., mucoceles, inflammatory fibrous hyperplasia or mucous 
retention cysts. With the passage of time, tongue piercings can produce a traumatic fibroma, a localised tumour that has the same colour as the mucosa and a soft consistency [5]; they can also generate fibrous repair tissue with re-epithelization of the perforated area [17].

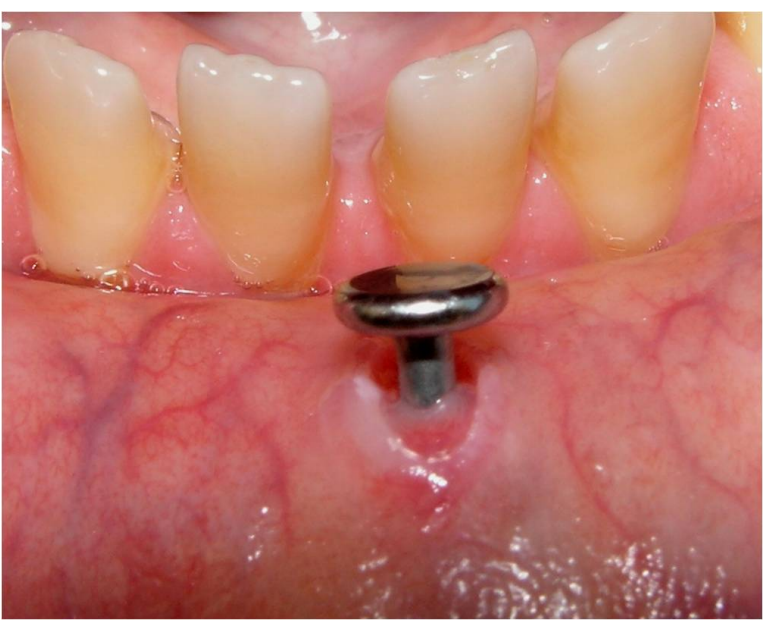

Fig. (3). Mucosal alteration produced by oral piercing.

A traumatic ulcer can also result from friction between oral/perioral jewellery and soft mouth tissue, characterised by brief painful episodes until removal of the jewellery [18]. Oral mucosa lesions can also be produced by repeated trauma of the jewellery on adjacent tissue, which can sometimes cause gingival recessions, abrasions or ulcerations [15]. Various studies have demonstrated a higher frequency of recessions in individuals with oral piercing than in those without, especially with the use of a "labret", which has been associated with Miller class I and II recessions [16]. Brooks et al. reported that tongue piercings produced gingival recession on the lingual aspect of lower front incisors and an increase in periodontal pocket depth. In the lower-lip piercings developed recessions on the buccal aspect of lower incisors after $6 \mathrm{wks}$ to $2 \mathrm{yrs}$ but with no increase in periodontal pocket depth [19]. A higher incidence of recession has been reported in the mandibular incisor area [8].

Because of the inflammation produced by tongue piercing, longer bars (> $20 \mathrm{~mm}$ ) are initially inserted, which are then reduced in size after 2 wks when the inflammation has abated $[2,4,6]$. Numerous researchers have described signs of gingival recession at $>2$ years after tongue piercing, more frequently observed with longer barbells [4, 20]. Other authors reported that perioral "labret" piercing produces gingival recession, influenced by the position and shape of the labret as well as by other risk factors, including age and sex. [16].

\section{DOES PIERCING PRODUCE BONE CHANGES?}

In oral/perioral piercings, constant trauma from the jewellery may produce localized horizontal bone loss [8]. Constant contact between jewellery and mandibular gingiva has been reported to cause bone dehiscence $[4,6]$.

\section{IS THERE A RELATIONSHIP BETWEEN PIERCING AND DENTAL ALTERATIONS?}

Changes to dental structure can be produced by parafunctional habits, e.g., bruxism, biting or pushing or by any type of play with piercing jewellery. These changes include fractures (Fig. 4), fissures, abrasions or the detachment of spicules of enamel [4-7]. If there is pulpal involvement, sensitivity to cold or sweet substances, pressure or even breathing can be produced [2]. A study by De Moore et al. in 2000 found some type of dental structure loss like enamel and dentine in $80 \%$ of patients with tongue piercings (22). This type of alteration is more frequent with the use of tongue barbells, especially in the molar and premolar area (with a higher prevalence on lingual cusps) and in lower incisors [46]. Dental fracture can also result from nerve block due to the local anaesthetic administered for the insertion [2]. Bearers of porcelain crowns have an increased risk of fractures or erosions if they also have oral piercing [21,22] and patients with large restorations or caries have an increased risk of cusp fractures [5]. Various authors have reported that contact between stainless steel piercing jewellery and silver amalgam can produce a galvanic current $(7,10)$ that may induce pulpal sensitivity. One author proposed a relationship between "labret" oral piercing and incisor linguoversion triggered by an imbalance of muscle forces [4].

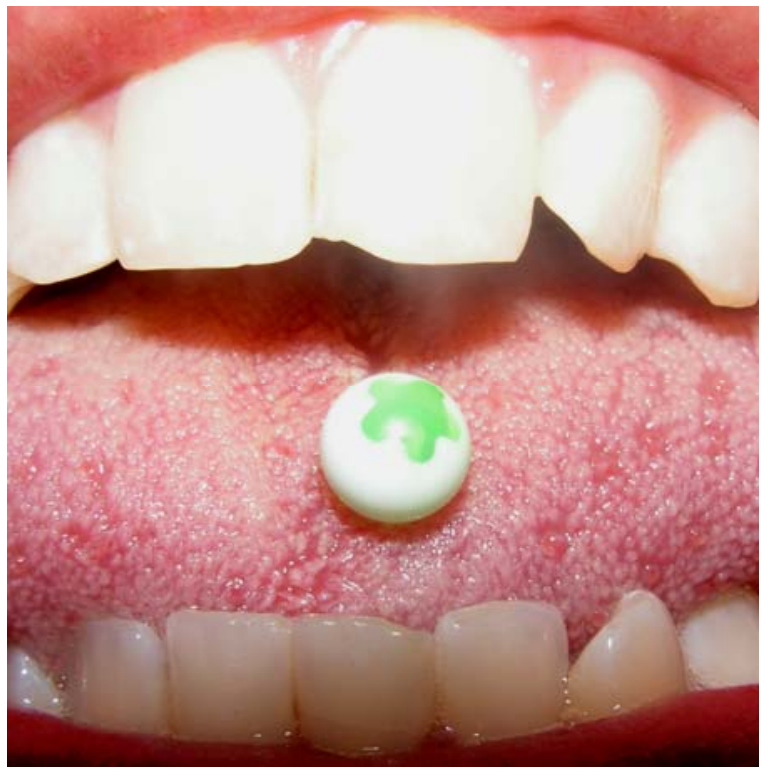

Fig. (4). Fracture of incisors due to a tongue piercing.

\section{DO PIERCINGS INFLUENCE SALIVA FORMATION?}

Several studies have confirmed that piercings in the oral/perioral cavity can stimulate salivary flow (sialorrhea) $[1,4,5,8]$. Thus, Venta et al. observed increased salivary flow in $63 \%$ of their series [20].

\section{ARE THERE ANY OTHER ADVERSE EFFECTS?}

The presence of piercing jewellery in the mouth, especially on the tongue, commonly hampers chewing, phonation and speaking and distorts the pronunciation of certain sounds, e.g., "s", "sh", "th", "ph", "t" or "v" [4-6, 8].

In piercings with barbells, labrets or rings, the jewellery can be ingested or aspirated, producing digestive or respiratory disorders, due to an incorrect fixing, poor handling during placement or exertion of high pressure, $[4,5]$. The risk of ingestion is higher with magnet piercing [5]. Considerable controversy has arisen over the need to remove oral piercing 
during surgery under general anaesthesia, avoiding the risk of ingestion/ aspiration of the jewellery or of trauma to tissue and the possible obstruction of intubation.

\section{CONCLUSION AND RECOMENDATION}

People with oral and perioral piercing have abnormalities in relation with them. Many young adult come to the clinic with specific problems The most hazardous oral sites for piercing are the uvula, due to the high risk of airway obstruction $[4,6]$, and the side of the tongue because the high number of blood vessel. The type of piercing jewellery most associated with buccal alterations is a long barbell in the tongue $[6,16,19]$. Jewellery should be exclusively composed of soft, hypoallergenic, non-toxic materials to minimise anaphylactic reactions and trauma to adjacent oral structures. The most affected oral site is at the lower incisors because the lost of gingival tissue [4, 5], largely due to tongue and lip piercings, with a high incidence of gingival recessions in this sector $[8,19]$. The most frequent oral lesions produced by piercings are inflammation, erythema and trauma to dental tissue and bone [4-6, 21, 23], and the most frequent traumas are tissue tears. The disease most commonly transmitted by piercing is hepatitis $[1,4,6]$. There is a need for greater awareness by dentists of these possible adverse effects and for a closer follow-up of patients with oral and perioral piercing.

Oral and perioral piercing is a strange device for our organism. Different pathologies can be the result of a response of oral and perioral piercing. Individuals with oral/perioral piercing should visit their dentist regularly for an exhaustive oral examination to ensure early detection of the various adverse effects associated with this practice. Could be interesting to have a classification to know the local an the systemic pathologies that the oral an perioral piercing can produced

\section{REFERENCES}

[1] Huber MA, Terezhalmy GT, Moore WS. Oral/perioral piercing. Quintessence Int 2003 ; 34(9): 722-3.

[2] Brennan M, O'Connell B, O'Sullivan M. Multiple dental fractures following tongue barbell placement: a case report. Dent Traumatol 2006 ; 22(1): 41-3.

[3] Berenguer G, Forrest A, Horning GM, Towle HJ, Karpinia K. Localized periodontitis as a long-term effect of oral piercing: a case report. Compend Contin Educ Dent 2006; 27(1): 24-7.
[4] De Urbiola Alís I, Viñals Iglesias H. Some considerations about oral piercings. Av Odontoestomatol 2005; 21(5): 259-69.

[5] Barbería Leache E, García Naranjo AM, González Couso R, Gutiérrez González D. Are the oral piercing important in the clinic? Dental Pract 2006; 1: 45-9.

[6] Peticolas T, Tilliss TS, Cross-Poline GN. Oral and perioral piercing: a unique form of self-expression. J Contemp Dental Pract 2000 ; 1(3): 30-46.

[7] Sardella A, Pedrinazzi M, Bez C, Lodi G, Carrassi A. Labial piercing resulting in gingival recession. A case series. J Clin Periodontol 2002 ; 29(10): 961-3.

[8] Levin L, Zadik Y, Becker T. Oral and dental complications of intra-oral piercing. Dent Traumatol 2005; 21(6): 341-3.

[9] Boardman R, Smith RA. Dental implications of oral piercing. J Calif Dent Assoc 1997; 25(3): 200-7.

[10] Dubose J, Pratt JW. Victim of fashion: Endocarditis after oral piercing. Curr Surg 2004 S; 61(5): 474-7.

[11] Guidard-Schmid JB, Picard H, Slama L, Masloc C, Amiel C, Pialox G . Piercing and its infectious complications. A public health issue n France. Presse Med 2000;29:1948-56.

[12] Friedel JM, Stehlik J, Desai M, Granato JE. Infective endocarditis after oral body piercing. Cardiol Rev 2003;11(5): 252-5.

[13] Perkins CS, Meisner J, Harrison JM. A complication of tongue piercing. Br Dent J 1997 22;182(4):147-8.

[14] Lhotka CG, Szekeres T, Fritzer-Szekeres M, et al. Are allergic reactions to skin clips associated with delayed wound healing?Am J Surg 1998; 176(4): 320-3.

[15] Bascones Martínez Figuero Elena. Periodontal diseases as bacterial infection. Av Periodontol Implantol 2005; 17(3): 111-8

[16] Leichter JW, Monteith BD. Prevalence and risk of traumatic gingival recession following elective lip piercing. Dent Traumatol 2006; 22 (1): 7-13.

[17] Lopez Jornet P, Vicente Ortega V, Yanez Gascon J, et al. Clinicopathological characteristics of tongue piercing: an experimental study. J Oral Pathol Med 2004; 33(6): 340-5.

[18] Bascones Martínez A, Figuero E, Esparza G. oral ulcers. Med Clin 2005; 125(15): 590-7.

[19] Brooks JK, Hooper KA, Reynolds MA. Formation of mucogingival defects associated with intraoral and perioral piercing: case reports. J Am Dent Assoc 2003; 134(7): 837-43.

[20] Venta I, Lakoma A, Haahtela S, Peltola J, Ylipaavalniemi P, Turtola L. Oral piercings among first-year university students. Oral Surg Oral Med Oral Pathol Oral Radiol Endod 2005; 99(5): 546-9.

[21] De Moor RJ, De Witte AM, De Bruyne MA. Tongue piercing and associated oral and dental complications. Endod Dent Traumatol $2000 ; 16(5): 232-7$.

[22] Botchway C, Kuc I. Tongue piercing and associated tooth fracture. J Can Dent Assoc 1998 ; 64(11): 803-5.

[23] Palacios-Sanchez B, Cerero-Lapiedra R, Campo-Trapero J, Esparza-Gomez G. Oral piercing: dental considerations and the legal situation in Spain. Int Dent J 2007; 57(2): 60-4. 